\title{
IMPACTOS DA PRODUÇÃO RECENTE DE MORADIA NA REGIÃO METROPOLITANA DO RECIFE (RMR) - PE
}

\section{IMPACTS OF HOUSING PRODUCTION IN THE METROPOLITAN REGION OF RECIFE (RMR) - PE}

\author{
A. Bárbara Ferragut \& B. José André Lopes \& C. Maria Angela Souza \\ Universidade Federal de Pernambuco, Brasil \\ ferragutbarbara@gmail.com \\ alopes.ricardo@gmail.com \\ souza.mariaangela@gmail.com
}

\begin{abstract}
RESUMO
Desde o início dos anos 2000, a Região Metropolitana do Recife vem passando por grandes mudanças econômicas e socioespaciais. Em grande parte, devido à chegada de grandes empreendimentos para a região, assim como o fomento governamental em políticas públicas que vieram a favorecer o mercado imobiliário, onde foram implantados empreendimentos imobiliários de grande e médio portes, voltados predominantemente para o mercado habitacional, de promoção tanto privada quanto pública. Nesse contexto, o Programa Minha Casa Minha Vida desempenhou um forte papel, embora não tenha cumprido suas prerrogativas iniciais, uma vez que prioriza sua oferta de moradia às faixas de rendas média e alta, minimizando $o$ atendimento aos nichos de mercado popular de menor renda. Os procedimentos metodológicos adotados compreendem a coleta de dados primários no portal do Ministério do Desenvolvimento Social, do Instituto Brasileiro de Geografia e Estatística (IBGE), da Caixa Econômica e a posterior alimentação de um banco de dados georreferenciado.
\end{abstract}

Palavras-chave: Dinamização econômica, Produção habitacional, PMCMV.

Linha de Investigação: 1: Cidade e projeto

Tópico: Estudos metropolitanos e territoriais

\section{ABSTRACT}

Since the early 2000s, the Metropolitan Region of Recife has been undergoing major economic and sociospatial changes. In large part, due to the arrival of large enterprises in the region, as well as governmental promotion in public policies that came to favor the real estate market, where large and medium-sized real estate projects were implemented, predominantly aimed at the housing market, both for private and public promotion. In this context, the Minha Casa Minha Vida Program has played a strong role, although it has not fulfilled its initial prerogatives, since it prioritizes its housing offer to the middle and upper income brackets, minimizing the service to lower-income popular market niches. The methodological procedures adopted 


\section{SÃOPAULO15 $17 \cdot$ LISBOA $25 \sim 26$ JUN 2020}

include the collection of primary data on the portal of the Ministry of Social Development, the Brazilian Institute of Geography and Statistics (IBGE), Caixa Econômica and the subsequent feeding of a georeferenced database.

Keywords: Economic dynamism, housing production, PMCMV.

Research line: 1: City and Project

Topic: Metropolitan and territorial studies

\section{Introdução}

A primeira política nacional que visava a redução do déficit habitacional entre as camadas mais populares da sociedade brasileira é implantada na década de 1940, por meio da Fundação da Casa Popular. Mas foi somente na década de 1960, com a instituição do Plano Nacional de Habitação (PNH) e do Sistema Financeiro de Habitação (SFH), seguido pela criação do Banco Nacional de Habitação (BNH) e das Companhias de Habitação (COHAB), em 1964, que a atuação do Estado na produção de habitação popular se torna significativa. Contudo, o público a que os recursos e os financiamentos habitacionais do BNH se destinavam originalmente, que abrangia o mercado popular, foi sendo deslocado para as camadas médias (famílias com rendimento de mais de cinco salários mínimos), causando uma baixa nas ofertas às camadas mais populares. Essa questão foi revertida, no final da década de 1970, com a introdução de programas subsidiados e destinados às famílias de até três salários mínimos, como "alternativos" ao programa convencional de "construção de conjuntos habitacionais". Em 1986, afetado pela crise, endividamento, altas taxas de inadimplência e baixo rendimento do FGTS, o BNH tem seu fim (Souza, 2009).

Entre o final da década de 1980, até meados dos anos 2000, as políticas públicas do Governo Federal para o controle do déficit habitacional apresentaram uma sucessão de programas, priorizando a gestão municipal, e alguns deles financiados com recursos de organismos internacionais. A partir de meados dos anos 2000, uma sequência de políticas de âmbito federal são implantadas, com impactos significativos, porém diferenciados, nas cidades brasileiras: uma política nacional de cunho social implantada por meio do Sistema Nacional de Habitação de Interesse Social (SNHIS), em 2005, seguida de políticas de caráter mais econômico implantadas por meio do Plano de Aceleração do Crescimento (PAC), criado em 2007, mais voltado para infraestrutura urbana, e do Programa Minha Casa Minha Vida (PMCMV), implantado em 2009, objeto de análise neste texto.

Comparado ao $\mathrm{BNH}$, devido ao caráter mais duradouro que apresenta, bem como ao volume de habitações produzidas, o PMCMV se assemelha por se viabilizar por meio da articulação entre Estado e capital financeiro, porém se diferencia em relação ao processo de contratação e de construção dos produtos ofertados, bem como em relação aos agentes produtivos. Ambos os programas apresentam um vetor econômico, visando a recuperação da economia por meio do setor imobiliário, gerando efeitos multiplicadores na indústria da construção civil e nos empregos com requisitos de baixa qualificação; e um vetor social, com perspectivas de atenuar a demanda de moradias. Possuem, também, um duplo sistema de crédito, destinado à produção, que aporta recursos financeiros para as empresas, e ao consumo, este por meio de financiamento de moradia às famílias beneficiadas (Souza, 2009).

Entre as premissas do PMCMV encontrava-se o combate ao déficit habitacional, contemplando a ampliação da oferta habitacional para famílias de renda de até 10 salários mínimos. Demonstra, assim, o interesse claro 


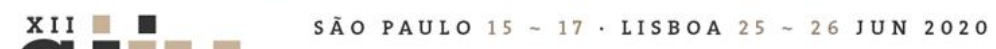

de impactar a economia pelos efeitos multiplicadores gerados a partir da indústria da construção. Foram adotadas medidas como aumento do volume de crédito na produção de habitações, associado à redução de juros, para viabilizar a aquisição do subsídio por parte dos interessados. A partir de estudos desenvolvidos pela Fundação João Pinheiro, o Governo Federal alocou os recursos conforme a estimativa do déficit habitacional de cada estado (Cardoso, 2013).

A meta inicial do PMCMV era a construção de um milhão de moradias em curto prazo, atendendo 3 faixas de renda, em conjunto com ações de infraestrutura urbana: para a faixa de 0-3 SM, 400 mil unidades; a de 3-6 SM, também 400 mil unidades; e a faixa de $6-10$ SM, a construção de 200 mil unidades ${ }^{1}$. Para as famílias com renda de até 3 salários mínimos, era oferecida uma linha de subsídio integral, com o pagamento de uma prestação simbólica de $\mathrm{R} \$ 50,00$.

Após o sucesso nas metas contratadas nos primeiros anos, em 2011 é lançado o PMCMV-2, com alocação de novos recursos e ajustes de ações, bem como reestruturação, a partir de críticas à primeira versão. No decorrer dos anos seguintes, devido à forte instabilidade política iniciada em 2014, o programa sofreu alterações tendo sua última versão lançada em 2018. Cabe ressaltar que, passados onze anos do lançamento do PMCMV, são indiscutíveis os seus efeitos socioespaciais, bem como a sua participação nas dinâmicas econômica e territorial das cidades e regiões metropolitanas brasileiras, entre essas a do Recife, objeto deste artigo.

A Região Metropolitana do Recife (RMR) vem passando por mudanças da sua dinâmica econômica, a partir dos anos 2000, sendo alvo de grandes empreendimentos industriais em áreas mais distantes da capital. A Fig. 01 apresenta os principais empreendimentos impulsionadores da economia e atratores do setor imobiliário implantados na RMR: o Complexo Industrial Portuário de Suape, ao sul da RMR (refletindo nos municípios do Cabo de Santo Agostinho, Jaboatão, Ipojuca e Moreno); a montadora da Fiat, uma indústria de vidros e um polo de produção de Hemoderivados, ao norte (Goiana ${ }^{2}$, recentemente integrada aos limites instituídos da Região Metropolitana, com impactos no município metropolitano de Abreu e Lima, Araçoiaba, Igarassu, Itapissuma, Itamaracá, Olinda e Paulista) e, em menor grau, a Arena Pernambuco e a Cidade da Copa, a oeste (atingindo São Lourenço da Mata e Camaragibe).

\footnotetext{
${ }^{1}$ Devido ao aumento do salário mínimo, hoje as faixas são divididas por valor em reais e não mais por quantidade de salários. Assim, a faixa 1 é para rendimento familiar até $R \$ 1.800,00$, faixa 2 para rendimento até $R \$ 4.000,00$ e faixa 3 para rendimento até $R \$ 7.000,00$, sendo ainda criada a faixa 1,5 cujo rendimento máximo previsto é de $R \$ 2.600,00$.

${ }_{2}^{2}$ No período inicial de pesquisa e coleta de dados o município de Goiana acabara de ser anexado à Região Metropolitana do Recife, em 2017, como uma das táticas do governo de Pernambuco para dinamização do polo norte do estado. Porém, em fevereiro de 2020,0 município deixa a RMR alegando ter sua autonomia reduzida frente a outros municípios por não possuir um contingente representativo no Conselho de Desenvolvimento Metropolitano.
} 


\section{SÃO PAULO15 17 LISBOA $25 \sim 26$ JUN 2020

do setor imobiliário e o processo de financeirização das cidades buscam a maximização dos lucros, cujas estratégias são apoiadas na transformação do solo. Ao adquirirem a propriedade fundiária, os grandes empreendedores assumem o papel de planejador urbano, parcelando o solo e garantindo a ele maior valor de mercado. Dessa forma, o poder público transfere para o setor privado o protagonismo das soluções urbanas.

\section{Metodologia}

Os dados apresentados neste trabalho são fruto de uma pesquisa de iniciação científica junto ao Observatório das Metrópoles - Núcleo Recife, coordenado pela terceira coautora. Seguindo os dois eixos metodológicos dos empreendimentos de promoção pública (PMCMV) e aqueles de promoção privada, os procedimentos metodológicos compreendem duas etapas: a primeira compreende a coleta de dados primários em duas fontes principais: o portal do Ministério do Desenvolvimento Regional, donde foram extraídos os dados para elaborar as tabelas referentes à quantidade de unidades habitacionais promovidas pelo PMCMV; e a Caixa Econômica Federal, donde foram coletadas informações para georreferenciar os empreendimentos imobiliários. Foram, também, coletadas informações no Instituto Brasileiro de Geografia e Estatística (IBGE); a segunda etapa consiste na alimentação de um banco de dados georreferenciados dos empreendimentos estudados, com produção de material gráfico e tabelas cartografias temáticas para apoiar a análise. Tal análise contemplou o contexto urbano/periurbano em que se inserem os empreendimentos imobiliários, incorporados ao acervo de informações do Observatório PE/ Núcleo Recife do Observatório das Metrópoles, Vale salientar que nem todos os empreendimentos contidos nos dados do Ministério foram georreferenciados, devido à falta de informação sobre a localização dos mesmos; no entanto, as informações presentes nesse banco de dados nos forneceram números relevantes que possibilitam sua análise.

Para análise dos dados, os municípios da metrópole do Recife foram reunidos segundo suas regiões sul, oeste e leste, além do polo que representa a cidade do Recife. Os empreendimentos foram agrupados segundo diversos critérios: 1) os municípios e as zonas em que estão localizados (norte, sul ou oeste); 2) o público a que se destina (MCMV faixa 1, MCMV faixa 1, 1/2, MCMV faixa 2, MCMV faixa 3 e empresariais); 3 ) a fase do PMCMV na qual o empreendimento foi contratado; 4) a tipologia habitacional proposta (condomínios verticais e horizontais fechados e bairros e cidades planejadas); e 5) a promoção pública pelo PMCMV e a promoção privada responsáveis pelos empreendimentos empresariais.

Buscou-se responder, neste artigo, duas questões de grande importância para a pesquisa:

(1) Qual o impacto do Programa Minha Casa, Minha Vida no déficit habitacional existente na metrópole do Recife durante seu período de atuação? Para isso, foram analisados os dados coletados, comparando os valores referentes a cada faixa de renda a fim de verificar se o programa atendeu às suas prerrogativas iniciais de promoção de habitação popular de baixo custo.

(2) Quais as condições de integração à dinâmica urbana local dos conjuntos e condomínios habitacionais implantados pelo PMCMV? Nesse contexto, foram analisados os empreendimentos georreferenciados, considerando a sua localização e sua proximidade com os núcleos urbanos existentes; sua promoção pelo PMCMV ou os empresariais; e a tipologia do empreendimento, visando verificar a inserção e o impacto dos empreendimentos no tecido urbano. 


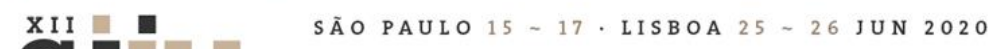

\section{Impactos dos Empreendimentos Habitacionais na Metrópole do Recife}

\subsection{0 balanço geral dos empreendimentos}

Os empreendimentos analisados possuem natureza diversa; no entanto, como mostra a Tabela 01, a promoção de habitação pelo Programa Minha Casa Minha Vida ganha destaque ao representar $91 \%$ dos empreendimentos, em contraposição aos $9 \%$ dos empresariais. Tal predominância ratifica a importância do programa como dinamizador do setor imobiliário privado, apesar de sua promoção ser pública, uma vez que a maioria dos empreendimentos são destinados às faixas 2 e $3(72 \%)$. Já as faixas de renda mais baixa, que correspondem ao maior déficit habitacional, representam $28 \%$ do total de empreendimentos.

A pesquisa levantou o maior número possível de empreendimentos localizados na Região Metropolitana do Recife, referentes ao período de 2006 a 2018. Foram registrados e georreferenciados 134 empreendimentos nos 15 municípios que compõem a RMR, sendo 120 promovidos pelo PMCMV e 12 promovidos pelo setor privado (empresariais). Desse conjunto, 51 (38\%) encontram-se localizados na região norte, que apresenta, em comparação com as demais regiões, o maior percentual de empreendimentos nas faixas 1 e $1 \frac{112}{2}(39 \%)$. Isso se deve, principalmente, ao fato de a produção habitacional estar ligada a uma demanda gerada pela implantação da montadora FIAT, e por esse polo ser o único que continua em plena atividade nos dias atuais. Os empreendimentos implantados na região sul somam além de 36 (27\%), onde somente 15\% atendem às faixas de mais baixas de renda. Já a na região oeste, que inclui o Recife, registra 47 (35\%) dos empreendimentos do PMCMV na RMR, onde $27 \%$ correspondem aos empreendimentos das faixas mais baixas. $1 \frac{1}{2}$ representam um terço $(33 \%)$ e os da faixa 3 correspondem a $10 \%$ do total de empreendimentos construídos pelo PMCMV. 


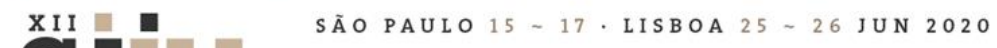

\begin{tabular}{|c|c|c|c|c|c|c|c|c|}
\hline \multirow[b]{3}{*}{ Polo } & \multirow[b]{3}{*}{ Município } & \multicolumn{5}{|c|}{$\begin{array}{l}\text { EMPREENDIMENTOS } \\
\text { GEORREFERENCIADOS }\end{array}$} & \multicolumn{2}{|c|}{ Promoção (\%) } \\
\hline & & \multicolumn{3}{|c|}{$0 \Sigma \cup \Sigma>$} & \multirow[b]{2}{*}{ 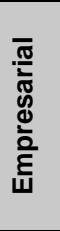 } & \multirow[b]{2}{*}{ 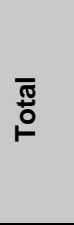 } & \multirow[b]{2}{*}{ 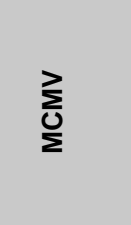 } & \multirow[b]{2}{*}{ 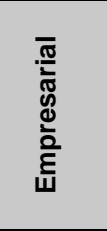 } \\
\hline & & 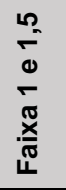 & $\begin{array}{l}\text { N } \\
\mathbb{\widetilde { x }} \\
\stackrel{\mathbb{\widetilde { W }}}{\mathbb{W}}\end{array}$ & $\begin{array}{l}m \\
\stackrel{m}{\widetilde{x}} \\
\stackrel{\mathbb{\varpi}}{\mathbb{1}}\end{array}$ & & & & \\
\hline \multirow{9}{*}{ Norte } & Abreu e Lima & 2 & 1 & 0 & 0 & 3 & $5,88 \%$ & $0,00 \%$ \\
\hline & Araçoiaba & 0 & 0 & 0 & 0 & 0 & $0,00 \%$ & $0,00 \%$ \\
\hline & Goiana & 1 & 0 & 0 & 0 & 1 & $1,96 \%$ & $0,00 \%$ \\
\hline & Igarassu & 5 & 11 & 0 & 0 & 16 & $31,37 \%$ & $0,00 \%$ \\
\hline & Itamaracá & 2 & 0 & 0 & 0 & 2 & $3,92 \%$ & $0,00 \%$ \\
\hline & Itapissuma & 0 & 0 & 0 & 0 & 0 & $0,00 \%$ & $0,00 \%$ \\
\hline & Olinda & 7 & 3 & 0 & 0 & 10 & $19,61 \%$ & $0,00 \%$ \\
\hline & Paulista & 3 & 13 & 3 & 0 & 19 & $37,25 \%$ & $0,00 \%$ \\
\hline & Sub-Total Norte & 20 & 28 & 3 & 0 & 51 & $100,00 \%$ & $0,00 \%$ \\
\hline \multirow{4}{*}{ Oeste } & Camaragibe & 0 & 8 & 0 & 2 & 10 & $17,02 \%$ & $4,26 \%$ \\
\hline & São Lourenço & 1 & 10 & 0 & 4 & 15 & $23,40 \%$ & $8,51 \%$ \\
\hline & Recife & 5 & 10 & 7 & 0 & 22 & $46,81 \%$ & $0,00 \%$ \\
\hline & Sub-Total Oeste & 6 & 28 & 7 & 6 & 47 & $87,23 \%$ & $10,64 \%$ \\
\hline \multirow{5}{*}{ Sul } & Cabo de Santo Agostinho & 1 & 0 & 0 & 4 & 5 & $2,78 \%$ & $11,11 \%$ \\
\hline & Jaboatão & 5 & 16 & 4 & 0 & 25 & $69,44 \%$ & $0,00 \%$ \\
\hline & Ipojuca & 1 & 2 & 0 & 2 & 5 & $8,33 \%$ & $5,56 \%$ \\
\hline & Moreno & 1 & 0 & 0 & 0 & 1 & $2,78 \%$ & $0,00 \%$ \\
\hline & Sub-Total Sul & 8 & 18 & 4 & 6 & 36 & $83,33 \%$ & $16,67 \%$ \\
\hline \multicolumn{2}{|r|}{ TOTAL } & 34 & 72 & 14 & 12 & 134 & $90,91 \%$ & $9,09 \%$ \\
\hline
\end{tabular}

Tabela 01 Empreendimentos localizados na Região Metropolitana do Recife georreferenciados pela pesquisa. Fonte: Caixa Econômica Federal (2019). Elaboração dos autores.

A produção empresarial, no entanto, apesar do número bem mais reduzido, ganha destaque especialmente na escala dos empreendimentos e no padrão mais elevado de renda. Localizam-se, em iguais proporções, nas regiões sul e oeste. Dois desses empreendimentos em cada uma dessas duas regiões são exemplares: Na região sul, a "Reserva do Paiva" é projetada e inicia sua implantação como empreendimento turísticoimobiliário destinado, predominantemente, à segunda residência de estrangeiros. Com a crise internacional de 2008, voltou-se para o mercado interno, inicialmente na perspectiva de absorver funcionários de alto escalão do Complexo Industrial Portuário de Suape, se constitui atualmente num "bairro planejado" voltado aos altos segmentos sociais que se deslocam do Recife para essa nova zona de dinamização econômica. O segundo exemplo é a "Cidade da Copa", projetada como Smart City no complexo que abriga a Arena da Copa do Mundo de 2014, localizado na região oeste da RMR, até hoje não implantada, devido à crise que se instalou no país a partir de 2014, que levou o distrato da Parceria Público Privada estabelecida para a implantação do complexo.

Os empreendimentos do tipo "bairros e cidades planejados" surgiram na década de 2010 , como a nova forma de moradia produzida pelo setor imobiliário na RMR, sendo recorrente em todos os polos de 


\section{SÃO PAULO15 $\sim 17 \cdot$ LISBOA $25 \sim 26$ JUN 2020

desenvolvimento. Uma nova tipologia que amplia a escala dos condomínios fechados, assumindo certas características apontadas por Souza e Bitoun (2015: 31)

São áreas de antigos latifúndios, outrora pertencentes à indústria açucareira, ou a sítios periurbanos, ou a proprietários, cujas terras, caracterizadas pelos atrativos naturais e ambientais, mantiveram-se como reserva de valor. A nova mercadoria passa a ser associada à paisagem urbana, ao meio ambiente, aos equipamentos de lazer e de segurança implantados como extensão da moradia, à infraestrutura de comércio e serviços a serem implantados para atendimento dos futuros moradores e de modo compatível com o seu padrão de consumo.

Muitos desse tipo de empreendimento foram projetados para a RMR, porém, tiveram sua implantação interrompida pela crise já referida de meados de 2010. Alguns desses, em função de sua escala, gerariam nos municípios receptores um aumento populacional desproporcional à capacidade de absorção da infraestrutura do município onde se localizaria. É o caso do projeto de "bairro planejado" Convida SUAPE, com entrega prevista para 2017, que geraria um incremento de mais de 50\% na população do município do Cabo de Santo Agostinho (Lima, 2014).

\subsection{O Programa Minha Casa Minha Vida}

Na aprovação do PMCMV foi previsto um fundo orçamentário repartido para as três faixas iniciais $(1,2$ e 3$)$ e uma meta de construção por faixa: 400 mil unidades habitacionais para a faixa 1; 400 mil para a faixa 2; e 200 mil para a faixa 3 , o que resultaria em $40 \%$ da produção destinada para a faixa 1 (na época renda até 3 salários mínimos), outros $40 \%$ da produção para a faixa 2 (de 3 a 6 salários mínimos) e $20 \%$ para a faixa 3 (de 6 a 10 salários mínimos) (Cardoso; Aragão, 2013).

Contudo, segundo a Tabela 02, dos empreendimentos contratados pelo PMCMV, a faixa 2 foi a faixa mais contemplada, com $58,4 \%$ das unidades concluídas. A faixa 1 , embora seja a segunda mais contemplada $(26,8 \%)$, sofreu muitos distratos, devido à crise financeira, e menos de $50 \%$ das unidades contratadas foram concluídas e entregues. Esses números também são justificados pela natureza do financiamento dessa faixa 1, que arrecada recurso do Governo Federal, através da Caixa Econômica Federal. Tal constatação leva a se concluir que o programa funcionou mais como um dinamizador econômico do que como combate ao déficit habitacional e que o setor privado foi o agente mais beneficiado, ao conceder a ele o papel fundamental para efetivação da produção de moradias.

\begin{tabular}{|c|c|c|c|c|c|c|}
\hline \multirow{2}{*}{ Faixa } & \multicolumn{4}{|c|}{ Unidades habitacionais } & \% em relação ao & \multirow{2}{*}{ Valor (R\$) } \\
\cline { 2 - 6 } & Contratadas & Concluídas & Entregues & Distratadas & (concluídas) & \\
\hline Faixa 1 & 23.272 & 10.875 & 10.148 & 4.283 & $26,75 \%$ & $879.609 .667,65$ \\
Faixa 1,5 & 1.279 & 987 & 857 & 0 & $1,47 \%$ & 0 \\
Faixa 2 & 50.794 & 42.135 & 35.951 & 0 & $58,39 \%$ & $173.261 .682,61$ \\
Faixa 3 & 11.645 & 6.517 & $4.589^{\star \star}$ & 0 & $13,39 \%$ & 0 \\
\hline Total & 86.990 & 60.514 & 51.545 & 4.283 & $100 \%$ & 1.052 .871 .350 \\
\hline
\end{tabular}

Tabela 02 Empreendimentos contratados pelo PMCMV por faixa de renda. Fonte: Ministério do Desenvolvimento Regional (2019). Elaboração dos autores. 


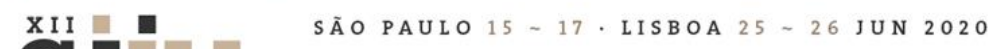

Os 120 empreendimentos do PMCMV (que somados aos 12 empreendimentos empresariais resultam no total de 134) correspondem a 844 contratos, muitos dos quais correspondem a um mesmo empreendimento imobiliário que foi fracionado em porções menores para atender às exigências do PMCMV, que define um limite de 500 unidades habitacionais por empreendimento. Considerando tais contratos, os municípios de Paulista e Jaboatão foram aqueles que mais subdividiram seus empreendimentos, tanto aqueles inseridos na faixa 1-13 em Paulista e 12 em Jaboatão - quanto os da faixa 2 - 86 em Paulista e 93 em Jaboatão. Admite-se que a inclinação do mercado, na produção dos empreendimentos faixa 2, pode caracterizar um nicho de mercado determinado por uma classe média em ascensão, assim como a implantação de empreendimentos em municípios periféricos pode representar a busca de menor valor do solo urbano, assim como sua disponibilidade e a flexibilidade das prefeituras na conversão de solo rural para solo urbano.

\begin{tabular}{|c|c|c|c|c|c|}
\hline \multirow[t]{2}{*}{ Polo } & \multirow[t]{2}{*}{ Município } & \multicolumn{3}{|c|}{$\begin{array}{c}\text { QUANTIDADE DE } \\
\text { EMPREENDIMENTOS }\end{array}$} & \multirow[t]{2}{*}{ TOTAL } \\
\hline & & Faixa 1 e 1,5 & Faixa 2 & Faixa 3 & \\
\hline \multirow{9}{*}{ Norte } & Abreu e Lima & 5 & 25 & 7 & 37 \\
\hline & Araçoiaba & 0 & 1 & 0 & 1 \\
\hline & Goiana & 1 & 10 & 2 & 13 \\
\hline & Igarassu & 10 & 52 & 10 & 72 \\
\hline & Itamaracá & 2 & 21 & 11 & 34 \\
\hline & Itapissuma & 0 & 16 & 2 & 18 \\
\hline & Olinda & 10 & 40 & 19 & 69 \\
\hline & Paulista & 13 & 86 & 21 & 120 \\
\hline & Sub-Total Norte & 41 & 251 & 72 & 364 \\
\hline \multirow{4}{*}{ Oeste } & Camaragibe & 0 & 49 & 15 & 64 \\
\hline & São Lourenço & 9 & 61 & 13 & 83 \\
\hline & Recife & 9 & 49 & 33 & 91 \\
\hline & Sub-Total Oeste & 18 & 159 & 61 & 238 \\
\hline \multirow{5}{*}{ Sul } & Cabo de Santo Agostinho & 8 & 23 & 13 & 44 \\
\hline & Jaboatão & 12 & 93 & 36 & 141 \\
\hline & Ipojuca & 2 & 15 & 8 & 25 \\
\hline & Moreno & 4 & 20 & 8 & 32 \\
\hline & Sub-Total Sul & 26 & 151 & 65 & 242 \\
\hline & TOTAL & 85 & 561 & 198 & 844 \\
\hline
\end{tabular}

Tabela 03 Quantitativo geral dos empreendimentos MCMV em Recife e RMR referentes às suas 3 fases. Fonte: Ministério do Desenvolvimento Regional (2019). Elaboração dos autores.

Os empreendimentos inseridos na faixa 3 se concentram no núcleo metropolitano - 33 em Recife e 36 em Jaboatão. Destinam-se a um nicho de mercado de maior poder aquisitivo, que pode arcar com um maior valor do solo como componente do preço final da habitação. Em números gerais, o principal foco do mercado são os empreendimentos faixa 2, com 561 empreendimentos, frente aos 85 referentes à faixa 1 e aos 198 da faixa 3. Percebe-se, também, a concentração de empreendimentos no polo norte da RMR, com 364 construções, movimento impulsionado pelo projeto do Governo do Estado de Pernambuco para a dinamização econômica do setor norte do estado.

O sucesso da primeira fase do Programa Minha Casa Minha Vida (entre os anos de 2009 e 2011), mencionado por Cardoso (2013), tem reflexo na Região Metropolitana do Recife, como demonstram as tabelas a seguir, que traçam um histórico da relação entre os empreendimentos contratados e concluídos. 
Conforme demonstra a Tabela 04 , nos empreendimentos faixa 1, houve uma equivalência de $100 \%$ entre contratos e execuções. Nas faixas 2 e 3, dos 207 empreendimentos contratados pela CAIXA, 204 foram concluídos, evidenciando impressionantes $97,10 \%$ de empreendimentos construídos em relação aos contratados.

\begin{tabular}{|c|c|c|c|c|c|c|c|c|}
\hline \multirow[t]{2}{*}{ Polo } & \multirow[t]{2}{*}{ Município } & \multicolumn{3}{|c|}{$\begin{array}{l}\text { Quantidade de Empreendimentos } \\
\text { Contratados }\end{array}$} & \multicolumn{3}{|c|}{$\begin{array}{l}\text { Quantidade de Empreendimentos } \\
\text { Concluídos (100\%) }\end{array}$} & \multirow{2}{*}{$\begin{array}{l}\text { Total } \\
\text { Geral }\end{array}$} \\
\hline & & faixa $1 / 1,5$ & faixa $2 / 3$ & total & faixa $1 / 1,5$ & faixa $2 / 3$ & total & \\
\hline \multirow{9}{*}{ Norte } & Abreu e Lima & 5 & 10 & 15 & 5 & 10 & 15 & $100 \%$ \\
\hline & Araçoiaba & 0 & 1 & 1 & 0 & 1 & 1 & $100 \%$ \\
\hline & Goiana & 0 & 3 & 3 & 0 & 3 & 3 & $100 \%$ \\
\hline & Igarassu & 2 & 14 & 16 & 2 & 14 & 16 & $100 \%$ \\
\hline & Itamaracá & 0 & 8 & 8 & 0 & 8 & 8 & $100 \%$ \\
\hline & Itapissuma & 0 & 1 & 1 & 0 & 1 & 1 & $100 \%$ \\
\hline & Olinda & 0 & 21 & 21 & 0 & 21 & 21 & $100 \%$ \\
\hline & Paulista & 4 & 29 & 33 & 4 & 28 & 32 & $96,96 \%$ \\
\hline & Sub-Total Norte & 11 & 87 & 98 & 11 & 86 & 96 & $97,95 \%$ \\
\hline \multirow{4}{*}{ Oeste } & Camaragibe & 0 & 10 & 10 & 0 & 10 & 10 & $100 \%$ \\
\hline & São Lourenço & 0 & 19 & 19 & 0 & 19 & 19 & $100 \%$ \\
\hline & Recife & 0 & 45 & 45 & 0 & 43 & 43 & $95,55 \%$ \\
\hline & Sub-Total Oeste & 0 & 74 & 74 & 0 & 72 & 72 & $97,29 \%$ \\
\hline \multirow{5}{*}{ Sul } & Cabo de Santo Agostinho & 0 & 5 & 5 & 0 & 5 & 5 & $100 \%$ \\
\hline & Jaboatão & 1 & 20 & 21 & 1 & 18 & 19 & $90,47 \%$ \\
\hline & Ipojuca & 0 & 2 & 2 & 0 & 1 & 1 & $50 \%$ \\
\hline & Moreno & 1 & 6 & 7 & 1 & 6 & 7 & $100 \%$ \\
\hline & Sub-Total Sul & 2 & 33 & 35 & 2 & 30 & 32 & $91,42 \%$ \\
\hline \multicolumn{2}{|r|}{ TOTAL } & 13 & 194 & 207 & 13 & 188 & 201 & $97 \%$ \\
\hline \multicolumn{2}{|r|}{ Total (\%) } & 6,28 & 93,72 & 100 & 6,46 & 93,54 & 100 & - \\
\hline
\end{tabular}

Tabela 04 Quantitativo de empreendimentos contratados e concluídos entre 2009 e 2011. Fonte: Ministério do Desenvolvimento Reaional (2019). Elaboracão dos autores.

Entre 2012 e 2015, a RMR segue a tendência nacional e amplia a quantidade de empreendimentos faixa 1 via Fundo de Arrendamento Residencial (FAR), saindo de 13 empreendimentos contratados para 37 entretanto, apenas 28 viriam a ser concluídos (75,67\%), como mostra a Tabela 05. Já nas faixas 2 e 3 a diferença é de 194 para 298, sendo executados 256 destes (85,9\%), o que representa, mesmo assim, o maior número de empreendimentos contratados e concluídos. Dessa forma, durante a segunda fase, 0 processo de financeirização da produção se demonstra ainda mais aparente nessas duas faixas de renda mais alta. 


\section{SÃOPAULO15 $\sim 17 \cdot$ LISBOA $25 \sim 26$ JUN 2020}

Seminário Internacional de Investigação em Urbanismo

\begin{tabular}{|c|c|c|c|c|c|c|c|c|}
\hline \multirow{2}{*}{ Polo } & \multirow{2}{*}{ Município } & \multicolumn{3}{|c|}{$\begin{array}{l}\text { Quantidade de Empreendimentos } \\
\text { Contratados }\end{array}$} & \multicolumn{3}{|c|}{$\begin{array}{l}\text { Quantidade de Empreendimentos } \\
\text { Concluídos (100\%) }\end{array}$} & \multirow{2}{*}{$\begin{array}{l}\text { Total } \\
\text { Geral }\end{array}$} \\
\hline & & faixa $1 / 1,5$ & faixa $2 / 3$ & total & faixa $1 / 1,5$ & faixa $2 / 3$ & total & \\
\hline \multirow{9}{*}{ Norte } & Abreu e Lima & 0 & 11 & 11 & 0 & 11 & 11 & $100 \%$ \\
\hline & Araçoiaba & 0 & 0 & 0 & 0 & 0 & 0 & - \\
\hline & Goiana & 0 & 3 & 3 & 0 & 3 & 3 & $100 \%$ \\
\hline & Igarassu & 4 & 28 & 32 & 4 & 23 & 27 & $84,40 \%$ \\
\hline & Itamaracá & 1 & 13 & 14 & 1 & 13 & 14 & $100 \%$ \\
\hline & Itapissuma & 0 & 8 & 8 & 0 & 8 & 8 & $100 \%$ \\
\hline & Olinda & 7 & 22 & 29 & 5 & 18 & 23 & $79,31 \%$ \\
\hline & Paulista & 4 & 39 & 43 & 3 & 37 & 40 & $93,00 \%$ \\
\hline & Sub-Total Norte & 16 & 124 & 140 & 13 & 113 & 126 & $90 \%$ \\
\hline \multirow{4}{*}{ Oeste } & Camaragibe & 0 & 27 & 27 & 0 & 20 & 20 & $74,10 \%$ \\
\hline & São Lourenço & 4 & 37 & 41 & 2 & 35 & 37 & $90,20 \%$ \\
\hline & Recife & 1 & 18 & 19 & 1 & 18 & 19 & $100 \%$ \\
\hline & Sub-Total Oeste & 5 & 82 & 87 & 3 & 73 & 76 & $87 \%$ \\
\hline \multirow{5}{*}{ Sul } & Cabo de Santo Agostinho & 8 & 14 & 22 & 7 & 14 & 21 & $95,45 \%$ \\
\hline & Jaboatão & 7 & 56 & 63 & 5 & 39 & 44 & $69,85 \%$ \\
\hline & Ipojuca & 0 & 10 & 10 & 0 & 5 & 5 & $50,00 \%$ \\
\hline & Moreno & 1 & 12 & 13 & 0 & 12 & 12 & $92 \%$ \\
\hline & Sub-Total Sul & 16 & 92 & 108 & 12 & 70 & 82 & $76 \%$ \\
\hline \multicolumn{2}{|r|}{ TOTAL } & 37 & 298 & 335 & 28 & 256 & 284 & $85 \%$ \\
\hline \multicolumn{2}{|r|}{ Total (\%) } & 11,3 & 88,7 & 100 & 6,91 & 93,09 & 100 & - \\
\hline
\end{tabular}

Tabela 05 Quantitativo de empreendimentos contratados e concluídos entre 2012 e 2015. Fonte: Ministério do Desenvolvimento Regional (2019). Elaboração dos autores.

A terceira e final fase do Programa, iniciada em 2018, se instala num momento em que o país está desestabilizado politicamente e com a economia em crise. O quantitativo de 2018 ainda demonstra uma quantidade de contratações equivalente à segunda fase, entre as três faixas, porém uma queda brusca na porcentagem de execução dos empreendimentos, que foi de $84,77 \%$ para $68,9 \%$, como mostra a Tabela 06 . Tendo uma atenção especial aos empreendimentos da faixa 1, dos 35 contratados apenas 6 foram concluídos, uma margem de quase $7 \%$ de todos os empreendimentos de 2018 , frente aos $93 \%$ das outras faixas.

Os dados demonstram que a faixa de subsídio mais beneficiada fora a de 3 a 6 salários mínimos, pois o retorno financeiro era significativamente maior e imediato, assim como a caracterização de um novo nicho de mercado formado pela classe média baixa. 


\section{SÃO PAULO15 17 LISBOA 25 26 JUN 2020}

\begin{tabular}{|c|c|c|c|c|c|c|c|c|}
\hline \multirow{2}{*}{ Polo } & \multirow{2}{*}{ Município } & \multicolumn{3}{|c|}{$\begin{array}{c}\text { Quantidade de } \\
\text { Empreendimentos Contratados }\end{array}$} & \multicolumn{3}{|c|}{$\begin{array}{l}\text { Quantidade de Empreendimentos } \\
\text { Concluídos (100\%) }\end{array}$} & \multirow{2}{*}{$\begin{array}{c}\text { Relação } \\
\text { Concluidos/ } \\
\text { Contratados } \\
(\%) \\
\end{array}$} \\
\hline & & faixa $1 / 1,5$ & faixa $2 / 3$ & total & faixa $1 / 1,5$ & faixa $2 / 3$ & total & \\
\hline \multirow{9}{*}{ Norte } & Abreu e Lima & 0 & 11 & 11 & 0 & 11 & 11 & $100 \%$ \\
\hline & Araçoiaba & 0 & 0 & 0 & 0 & 0 & 0 & - \\
\hline & Goiana & 1 & 6 & 7 & 0 & 5 & 5 & $71 \%$ \\
\hline & Igarassu & 4 & 20 & 24 & 2 & 18 & 20 & $83,30 \%$ \\
\hline & Itamaracá & 1 & 11 & 12 & 0 & 11 & 11 & $92 \%$ \\
\hline & Itapissuma & 0 & 9 & 9 & 0 & 9 & 9 & $100 \%$ \\
\hline & Olinda & 3 & 16 & 19 & 0 & 14 & 14 & $73,70 \%$ \\
\hline & Paulista & 5 & 39 & 44 & 2 & 23 & 25 & $56,80 \%$ \\
\hline & Sub-Total Norte & 14 & 112 & 126 & 4 & 91 & 95 & $75 \%$ \\
\hline \multirow{4}{*}{ Oeste } & Camaragibe & 0 & 27 & 27 & 0 & 16 & 16 & $59,25 \%$ \\
\hline & São Lourenço & 5 & 18 & 23 & 2 & 15 & 17 & $73,90 \%$ \\
\hline & Recife & 8 & 19 & 27 & 0 & 13 & 13 & $48 \%$ \\
\hline & Sub-Total Oeste & 13 & 64 & 77 & 2 & 44 & 46 & $60 \%$ \\
\hline \multirow{5}{*}{ Sul } & Cabo de Santo Agostinho & 0 & 17 & 17 & 0 & 16 & 16 & $94,10 \%$ \\
\hline & Jaboatão & 4 & 53 & 57 & 0 & 30 & 30 & $52,63 \%$ \\
\hline & Ipojuca & 2 & 11 & 13 & 0 & 11 & 11 & $84,60 \%$ \\
\hline & Moreno & 2 & 10 & 12 & 0 & 10 & 10 & $83 \%$ \\
\hline & Sub-Total Sul & 8 & 91 & 99 & 0 & 67 & 67 & $68 \%$ \\
\hline & TOTAL & 35 & 267 & 302 & 6 & 202 & 208 & $69 \%$ \\
\hline & Total (\%) & 11,3 & 88,7 & 100 & 6,91 & 93,09 & 100 & - \\
\hline
\end{tabular}

Tabela 06 Quantitativo de empreendimentos contratados e concluídos entre 2016 e 2018. Fonte: Ministério do Desenvolvimento Regional (2019). Elaboração dos autores.

\subsection{A Localização dos Empreendimentos na Região Metropolitana do Recife}

Ao avaliar a produção viabilizada pelo PMCMV nos polos de desenvolvimento da região metropolitana do Recife, o norte se destaca pela presença mais acentuada de empreendimentos. Segundo Cavalcanti (2010), isso se deve ao fato dessa produção habitacional estar aliada a uma demanda que se manteve ao longo do tempo, gerada pelas oportunidades de emprego que surgiram com a chegada de grandes empreendimentos industriais no polo. No entanto, é na porção norte que também se observa uma maior falta de conexão entre os empreendimentos imobiliários e os núcleos urbanos existentes.

A região sul, como dito anteriormente, é a que apresenta o menor número de empreendimentos totais, dos quais $50 \%$ são voltados para a faixa 2 , que predomina em todos os polos. Os empreendimentos voltados para essa faixa são os mais presentes na pesquisa. Juntos, eles representam $58,39 \%$ das unidades habitacionais concluídas pelo Programa, com um total de 42.135 moradias prontas para o uso. 


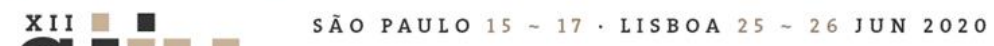

Seminário Internacional de Investigação em Urbanismo

Seminario Internacional de Investigación en Urbanismo

É possível, ainda, notar uma grande desarticulação do programa com a política urbana dos municípios, principalmente pelo fato dos empreendimentos, via de regra, estarem localizados em áreas longínquas e carentes de infraestrutura e equipamentos urbanos. No entanto, uma parcela dos empreendimentos se conecta com os núcleos urbanos existentes, relativamente próximos do centro das suas respectivas cidades e se integram à malha urbana (Fig. 02).

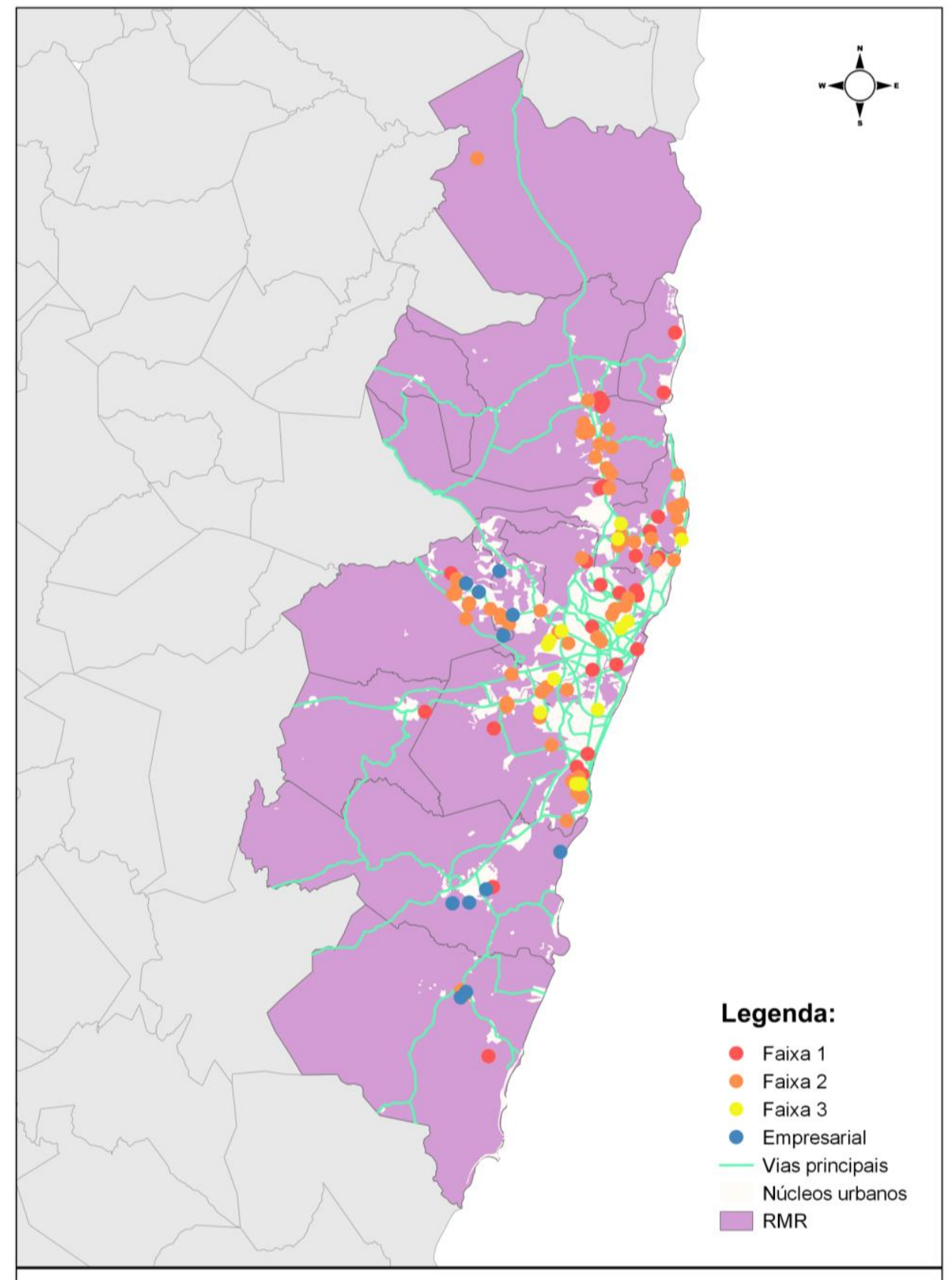

Fig. 02 Empreendimentos georreferenciados pela pesquisa. Fonte: Caixa Econômica Federal (2019). Elaboração dos autores. 


\section{SÃO PAULO15 17 LISBOA $25 \sim 26$ JUN 2020 \\ Seminário Internacional de Investigação em Urbanismo

No processo de pesquisa constata-se, como exposto na Tabela 07, que, considerando o tipo do empreendimento (empresarial ou público), os imóveis mais produzidos e, consequentemente, entregues, foram aqueles que tinham parcerias com o Programa Minha Casa, Minha Vida (públicos), com predominância da tipologia "Conjunto habitacional - Condomínio vertical fechado" ao Norte, "Conjunto habitacional -

\begin{tabular}{|c|c|c|c|c|c|c|c|c|c|c|c|}
\hline \multirow[b]{2}{*}{ POLOS } & \multicolumn{5}{|c|}{$\begin{array}{l}\text { EMPREENDIMENTOS } \\
\text { GEORREFERENCIADOS }\end{array}$} & \multicolumn{2}{|c|}{ Promoção (\%) } & \multicolumn{4}{|c|}{ TIPOLOGIA } \\
\hline & 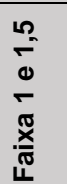 & 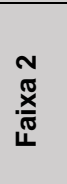 & 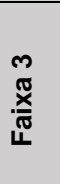 & 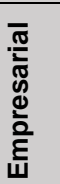 & बَّ & 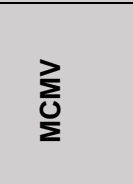 & 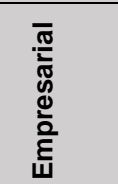 & 을 $\frac{\frac{0}{\sigma}}{\frac{\pi}{d}}$ & 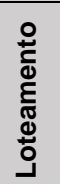 & 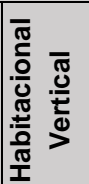 & 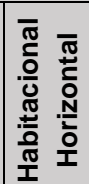 \\
\hline Norte & 20 & 28 & 3 & 0 & 51 & $100,00 \%$ & $0,00 \%$ & 0 & 5 & 29 & 17 \\
\hline Oeste & 6 & 28 & 7 & 6 & 47 & $87,23 \%$ & $10,64 \%$ & 0 & 3 & 35 & 8 \\
\hline Sul & 8 & 18 & 4 & 6 & 36 & $83,33 \%$ & $16,67 \%$ & 5 & 2 & 24 & 5 \\
\hline TOTAL & 34 & 56 & 14 & 12 & 134 & $91,04 \%$ & $8,21 \%$ & 5 & 10 & 88 & 30 \\
\hline
\end{tabular}

Tabela 07 Empreendimentos localizados na Região Metropolitana do Recife georreferenciados pela pesquisa. Fonte: Caixa Econômica Federal (2019). Elaboração dos autores.

Condomínio vertical fechado" a Oeste e "Conjunto habitacional - Condomínio vertical fechado" ao Sul.

A Tabela 07 mostra como as tipologias habitacionais predominantes em cada polo estão associadas à faixa de renda a que se destinam. Ao norte, são mais recorrentes os empreendimentos habitacionais e verticais destinados às faixas $1,1,5$ e 2 , o que pode ser explicado pela chegada da classe trabalhadora das indústrias. Já a oeste, encontra-se uma predominância dos habitacionais verticais, sendo mais frequentes os empreendimentos voltados para a faixa 2, possivelmente pela chegada da classe média alta atraída pela Cidade da Copa. No polo sul, observa-se uma maior recorrência dos empreendimentos voltados para a faixa 2 e uma predominância tipológica dos habitacionais verticais. É possível notar, também, que esse polo é o único que apresenta a tipologia dos bairros planejados, que decorre principalmente da expectativa gerada pelo Porto de SUAPE e pela chegada que uma classe média alta na região.

A Fig. 03, extraída de Costa (2015), mostra que a maioria dos empreendimentos do PMCMV voltados para as faixas de renda 2 e 3 ocupa áreas que já têm uma urbanização mais consolidada, em sua maioria áreas de assentamentos populares. No entanto, em alguns outros casos, esses empreendimentos são implantados em áreas de canaviais, sítios e granjas, ricas em recursos naturais. Esse padrão na escolha dos terrenos das faixas de renda 2 e 3 demonstra uma generalização, como afirma Costa (2019) onde se busca terrenos em zonas periféricas que ainda não possuem valorização imobiliária e que contam com grandes áreas disponíveis, mas que são dotados de acesso ao transporte público e são próximos do centro. 


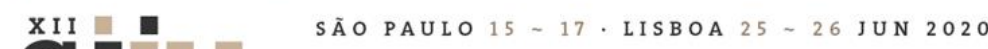

Seminário Internacional de Investigação em Urbanismo

Seminario Internacional de Investigación en Urbanismo

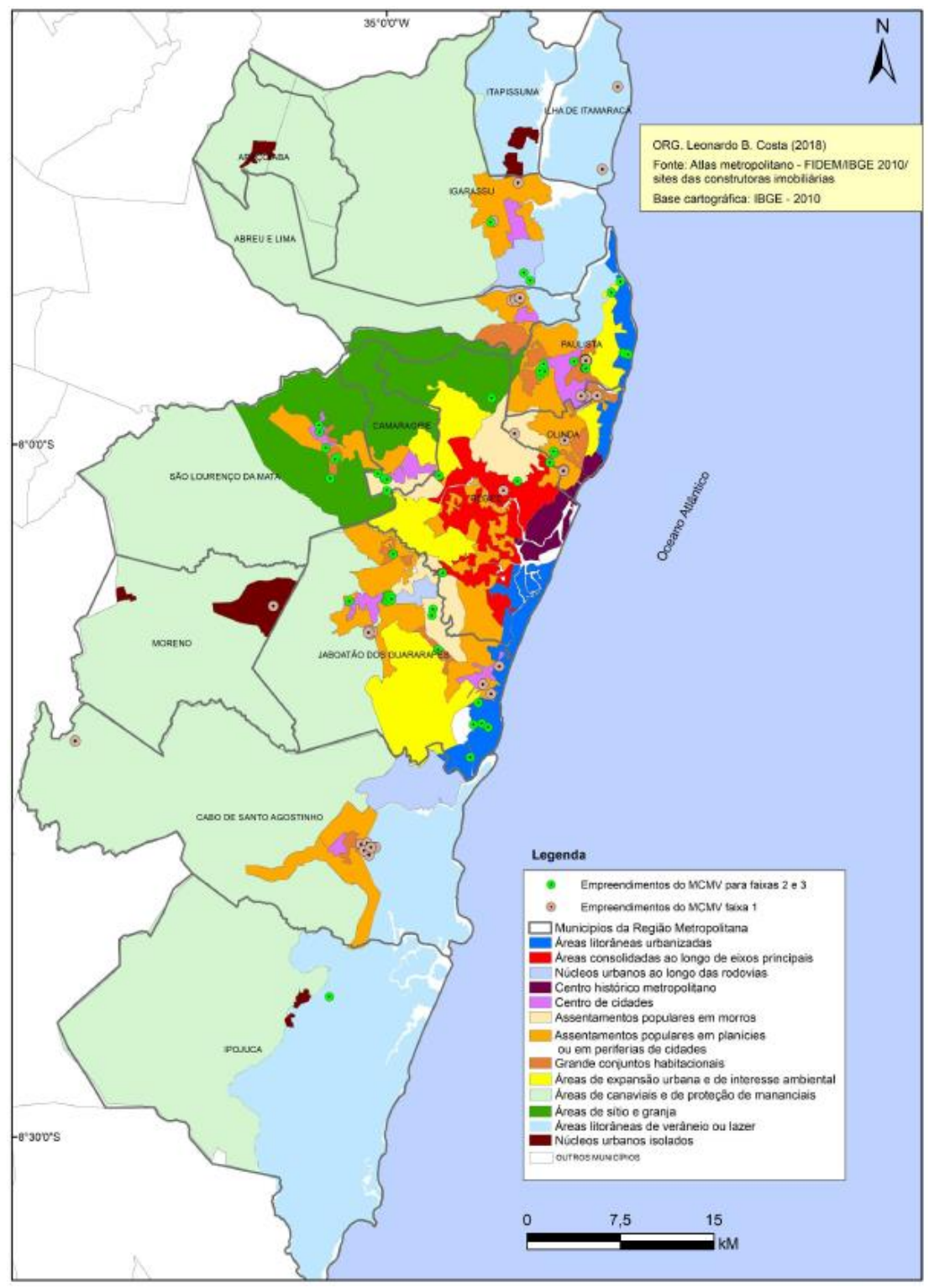

Fig. 03 Localização dos empreendimentos do PMCMV em relação as categorias das macro unidades metropolitanas. Fonte: COSTA (2019).

\section{Considerações Finais}

Os resultados acima apresentados caracterizam o que vem a ser os empreendimentos imobiliários que foram lançados para as zonas de expansão da Região Metropolitana do Recife, onde foram implantados ou a previsão de sê-los. É possível tecer uma avaliação crítica quanto à estruturação do Programa Minha Casa Minha Vida e sua eminente monetarização massiva. Conforme suas fases, foi se afirmando enquanto um 


\section{SÃOPAULO15 $17 \cdot$ LISBOA $25 \sim 26$ JUN 2020}

programa focado na criação de habitação e manutenção do mercado ativo durante a crise; reforçando seus compromissos econômicos em detrimento dos sociais.

O PMCMV apresenta uma margem de $71,69 \%$ dos empreendimentos destinados às faixas 2 e 3 durante 0 seu período de atuação. Especialmente na última fase, entre 2016 e 2018, 7\% dos empreendimentos foram destinados à faixa 1 em contraponto a $93 \%$ das faixas 2 e 3 . Os dados acima corroboram o entendimento de uma financeirização do programa, afetando principalmente a faixa 1, onde o déficit habitacional, de fato, seria minimizado.

A construção dos empreendimentos faixa 1 mostra-se menos interessante às construtoras, somada aos altos índices de distratos e à liberdade nas escolhas dos terrenos, acarretando problemas durante as fases de construção até a ocupação dos conjuntos. A localização dos terrenos da faixa 1 é uma das características mais marcantes no modelo aplicado na RMR, onde a maioria dos conjuntos permaneceu distante dos centros urbanos e das ofertas de trabalho formal.

Quanto à qualidade das localizações, os municípios que já detinham reservas de terrenos destinados à Habitação de Interesse Social, conferiram uma melhor desempenho na implementação desses conjuntos habitacionais; os demais, que acataram as localidades escolhidas pelas incorporadoras/construtoras, acabaram por criar alguns novos sítios urbanos desconectados dos tecidos existentes e sem relações próximas com as localidades nas quais estão inseridos.

As localizações dos empreendimentos, mesmo que de promoção pública, caracterizam um movimento de mercado, uma troca de protagonismo entre os setores público e o privado no planejamento territorial que, de forma intrínseca, definem quem tem o direito pleno aos serviços oferecidos pela vida urbana.

\section{BIBLIOGRAFIA}

CARDoso, A. L.; ARAGÃO, T. (2013). Do fim do BNH ao Programa Minha Casa Minha Vida: 25 anos de política Habitacional no Brasil. In:CARDOSO A. L. (Org.). O Programa Minha Casa Minha Vida e seus Efeitos Territoriais.Rio de Janeiro: Letra Capital.

CAVALCANTI, H.; SOUZA, M. A.; OLIVEIRA, R. S. (2019). Desenvolvimento em Questão. Impactos do Complexo Industrial Portuário de Suape (CIPS): migração, trabalho, condições de moradia, identidade e novas territorialidades. Recife: Massangana.

CAVALCANTI, M. (2010). As Inovações da Oferta Imobiliária no Produto Residencial: um estudo sobre os Condomínios Resorts no Recife. Dissertação (Mestrado em Desenvolvimento Urbano). Universidade Federal de Pernambuco, Recife.

CHESNAIS, F. (2010). Alguns elementos sobre o capitalismo contemporâneo e a crise econômica e financeira mundial. In: LEAL, S.; LACERDA, N. Novos Padrões de Acumulação Urbana na Produção do Habitat: Olhares Cruzados Brasil - França. Recife: Ed. Universitária da UFPE, p. 15-31.

COSTA, L. B. (2019). A estrutura imobiliária da Região Metropolitana do Recife: a mercadoria habitação como promotora da fragmentação do urbano. Tese (Doutorado em Geografia). Recife: Programa de PósGraduação em Geografia/ Universidade Federal de Pernambuco. 


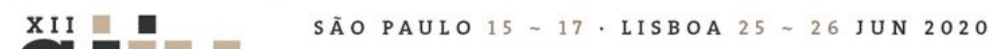

ESIG, Prefeitura do Recife. Disponível em: https:/esigportal.recife.pe.gov.br/arcgis/apps/webappviewer/ index.html?id=679e74b46c7b44caaad64abd5f751b4b. Acesso em 11 nov. 2019.

FEDERAL, Caixa Econômica. Base de dados, 2019.

FEDERAL, Governo. Ministério do Desenvolvimento Regional. Disponível em: https://www.mdr.gov.br/. Acesso em: 11 nov. 2019.

HARVEY, D. (2004). O Novo Imperialismo. São Paulo: Loyola.

LIMA, J. (2014). Inovações no produto imobiliário: o modelo de "cidades e bairros planejados" como paradigma de uma nova governança? Dissertação de Mestrado. Recife: MDU/UFPE.

Do gerenciamento ao empresariamento: a transformação da administração urbana no capitalismo tardio, In Espaço e debates n. 39. São Paulo, 1996, p. 48-64.

D. The Right of the City. The New Left Review, (53) set-out, 2008 [http://www.newleftreview.org/? page=article \&view=2740]

. O enigma do capital: e as crises do capitalismo. São Paulo: Boitempo, 2011.

MIRANDA, L. I. B. (2008). Produção do espaço e planejamento em áreas de transição ruralurbana: o caso da Região Metropolitana do Recife - PE. Tese (Doutorado em Desenvolvimento Urbano). Recife: Programa de Pós-Graduação em Desenvolvimento Urbano/ Universidade Federal de Pernambuco.

SOUZA, M. A..; BITOUN, J. (orgs.) (2015). Recife: Transformações na ordem urbana 1980-2010. RIBEIRO, L.C.Q. (coord.). Série Metrópoles: Território, Coesão Social e Governança Democrática. 1. ed. - Rio de Janeiro: Letra Capital e Observatório das Metrópoles [Eletrônico_ ISBN: 978-85-7785-343-4], 538 p.

SOUZA, M. A. et all. (2015). As formas de provisão da moradia na configuração socioespacial da Região Metropolitana do Recife In SOUZA, M A.A.; BITOUN, J. (orgs.) Recife: Transformações na ordem urbana. RIBEIRO, L.C.Q. (coord). Série 1. ed. - Rio de Janeiro: Letra Capital [impresso_ISBN: 978-85-7785-342-7] [Eletrônico_ISBN: 978-85-7785-343-4], pp. 241-285. 